Meta

Journal des traducteurs

Translators' Journal

\title{
Transcending the Discourse of Accuracy in the Teaching of Translation: Theoretical Deliberation and Case Study
}

\section{Yong Zhong}

Volume 47, numéro 4, décembre 2002

URI : https://id.erudit.org/iderudit/008037ar

DOI : https://doi.org/10.7202/008037ar

Aller au sommaire du numéro

Éditeur(s)

Les Presses de l'Université de Montréal

ISSN

0026-0452 (imprimé)

1492-1421 (numérique)

Découvrir la revue

Citer cet article

Zhong, Y. (2002). Transcending the Discourse of Accuracy in the Teaching of Translation: Theoretical Deliberation and Case Study. Meta, 47(4), 575-585. https://doi.org/10.7202/008037ar
Résumé de l'article

La pratique de la traduction en Chine et en Australie est influencée par un discours sur l'exactitude en traduction (fidélité, objectivité en traduction). L'auteur décrit en trois sections comment il a été inspiré par des théories critiques récentes pour réorienter son enseignement hors du discours sur l'exactitude. 


\title{
Transcending the Discourse of Accuracy in the Teaching of Translation: Theoretical Deliberation and Case Study
}

\author{
YONG ZHONG \\ University of New South Wales, Sydney, Australia
}

\begin{abstract}
RÉSUMÉ
La pratique de la traduction en Chine et en Australie est influencée par un discours sur l'exactitude en traduction (fidélité, objectivité en traduction). L'auteur décrit en trois sections comment il a été inspiré par des théories critiques récentes pour réorienter son enseignement hors du discours sur l'exactitude.
\end{abstract}

\begin{abstract}
The practice of translation in China and Australia has been influenced by a discourse of accuracy, which requires translations to be accurate, faithful, objective and impartial, etc. In the teaching of translation, this discourse has translated into a pedagogy that is centred on rules (i.e., criteria, standards and authority), that tends to rely on mechanical drills to enforce those rules and that dis-empowers students by turning them into innocent precision instruments. In three sections, the author of this article will discuss how he has been inspired by recent critical theories to reorient his teaching out of the discourse of accuracy.
\end{abstract}

\section{MOTS-CLÉS/KEYWORDS}

Chinese-English translation, accuracy, subjectivity, empowerment, meaning closure

\section{An accurate paradox}

Before I explain what I mean by an accurate paradox, I would first like to tell how I have come to identify this paradox by relating to my own experiences as a translation practitioner and educator.

As a translation practitioner with Chinese and Australian experiences, I reckon that the practice of Chinese-English translation in the two countries has been motivated with a strong aspiration to achieve total equivalence between the source language (SL) and target language (TL) texts. It is often thought that a good translation is one that reincarnates the truth, all the truth, nothing but the truth inherent and coherent in both the content and form of the SL text ${ }^{1}$. Generally speaking, it is a huge compliment to say to Chinese translators that their rendition has satisfied the criteria of $\underline{\text { xin, }} \underline{\mathrm{da}}$ and ya, which usually mean producing a rendition that is completely equivalent to the original text in meaning, expression and style. Likewise, many Australian practitioners feel flattered when they are declared accurate translators. Few practitioners in either country are happy to have themselves declared creative translators and even fewer are not offended when their rendition is deemed inaccurate.

As an educator with Chinese and Australian experiences, I believe that, likewise, the training of Chinese-English translators in the two countries has been obsessed 
with producing accurate practitioners. Translation curricula often consist of secluded, individualist and single-minded exercises designed for indoctrinating criteria of equivalence, imposing specific techniques to achieve equivalence and inducing trainees to internalize the specified criteria and techniques. For example, many educators would emphatically and repeatedly exhort trainees to follow a number of seemingly universal criteria, such as the previously mentioned xin, da and ya. They would design various exercises and drills for enforcing the criteria and for disciplining the trainees in their academic pursuit. They would also use the criteria to assess the performance and progress of the trainees, rewarding those who conform to the criteria and punishing those who deviate from the criteria. In short, to a large extent, the teaching of translation is often about establishing and preserving criteria and involves little mentioning that the criteria, of which accuracy is most central and prominent, are largely subjective constructs.

I do not intend to ridicule the professionalism of many practitioners and educators who are dedicated to accuracy. After all, translation is a process of crosslanguage and cross-cultural communication of information, in which a fair degree of accuracy plays an important role, and the livelihood of practitioners depends on their ability to facilitate that process of communication. The point I am making is that the concern with accuracy has become an excessively elusive, exclusive and dominant discourse in the practice and teaching of translation, which has tended to drown other discourses. Indeed, I challenge my colleagues and readers to name other criteria or catchwords that they have heard talked about in the profession. Maybe there are objectivity, impartiality, neutrality, faithfulness and loyalty. But these are more or less synonymous to each other and to accuracy and, together with the latter, comprise the discourse of accuracy.

Discourse, a concept first explored by the French theorist Michel Foucault in the 1970's, refers to the relationship between language, social institutions, subjectivity and power. Different discourses offer different and competing ways of giving meaning to the world and of structuring social institutions and activities. What is more important, not all discourses carry equal weight or power. According to Weedon: "Some account for and justify the appropriateness of the status quo. Others will give rise to challenge to existing practices from within or will contest the very basis of current organisation and the selective interests which it represents" (1998, p. 179). I argue that the discourse of accuracy, which is so dominant as to drown the other discourses in the field of translation and translation education, has also tended to account for and justify the appropriateness of conventional translation practice and teaching.

While recognizing its frequently cited merits and virtues, I see a number of pitfalls with the dominant discourse of accuracy, especially in relation to the teaching of translation. First of all, the discourse reduces the teaching to a mechanical process of indoctrinating standards and techniques. Let's look at the teaching activities we use to train students and at the contents page of the many textbooks we use for our courses. Is it not true that many of them teach how to conform with the standards, how to find equivalence between languages and cultures and how to accurately render nouns, verbs, adjectives, clauses, short sentences, complex sentences, etc., from one language into another? If the process involves any thinking at all, it is often limited to some primary thought needed for determining the right meaning of the SL 
text, searching for the right words in the TL text and comparing which rendition is the best equivalence.

Secondly, the discourse centres the teaching on the explication of standards, of rules, of do's and don'ts, which it takes for granted. As an educator, I used to take great efforts to explain the criteria to my students and to explain what I meant by accuracy. I was challenged time and again by some students who believed that what I regarded as accurate was actually inaccurate. As well, there were other students who believed that what I regarded as accurate was really accurate, simply because I as an educator was presumably more knowledgeable and experienced-which means that authority and hierarchy came to my rescue as the most effective weapon for quelling classroom revolts. I would like to think that many of my colleagues share these experiences of mine.

Thirdly, the discourse dis-empowers the trainee practitioners. The emphasis on accuracy subjects them to a relationship of loyalty to the SL text. Other requirements of the discourse, such as objectivity, faithfulness and loyalty, are also meant to deprive them of their subjectivity. In Australian classrooms, they are repeatedly reminded that a translator is merely a language aide who has no other roles except parroting accurately and objectively what other people have said. According to a publication (videotape and script) by the National Accreditation Authority for Translators and Interpreters, a good translator is one who "makes himself or herself the facilitator, not the focus of the process" (NAATI 1990, p. 10). Many Chinese practitioners have as little, if not even less, power because, as Zhong Su-kong put it, a good translator was a "cog and wheel' in the whole revolutionary machine" (1980, p. 3). That is, he/she is an instrument without subjectivity or autonomous thinking. In both situations, translators tend to be constructed as powerless, intellectually inadequate instruments. ${ }^{2}$

The pitfalls of the discourse of accuracy discussed above are similar to the characteristics of a non-thinking teaching environment identified by Onosko and Newmann (1994). According to them, a view of teaching as knowledge transmission, a bloated curriculum, teachers' low expectations of students, and intellectually oppressive teaching structure and isolated learning were barriers to creative teaching and learning. In relation to the teaching of translation, I believe that the pitfalls have contributed to the loss of attraction and appeal of translation courses to students. Who would like to spend so many years struggling through universities only to become a mere language aide or facilitator, a mechanical language converter, or a cog and wheel? Whenever I use any teaching materials that instruct students to shape themselves into facilitators, I cannot help feeling that I see on their faces expressions of disappointment, humiliation and disillusionment—what a terribly guilty feeling. But what if I choose not to use those materials? I would also feel uneasy because they teach the so-called norms in the profession and because the courses are supposed to produce language aides, facilitators, and cogs and wheels. It is this dilemma that has made me aware of the accurate paradox. While university education is intended to enjoin students to love themselves, to nurture their egos, and to enhance their imaginative and creative potentials, we train them to be mindless, unthinking and mechanical language facilitators by subjugating them to the discourse of accuracy. 


\section{Thinking one's way out of the accurate impasse}

The point that I have been trying to make in this paper is that the discourse of accuracy pushed me and, presumably, many of my colleagues, into an impasse. It is post-liberal theories, ranging from post-structuralism, to cultural studies and to feminism that has helped me become aware of the pitfalls of the discourse of accuracy. It is impossible to review the whole new world of literature here and so I will only briefly mention three scholars whose theories were responsible for my enlightenment. Barthes (1977) announced the "death" of the author as he pointed out rhetorically that a finished text was independent of and immune to any possibility of being unified or closed by any notion of what the author might have intended. Stuart Hall (1980) argued in his preferred reading theory that a text was always subjected to a multiplicity of readings, including what he classified as negotiated and aberrant readings even though it was largely the making of the author and might invite a preferred reading. John Fiske $(1987,1998)$ theorised semiotic democracy, which went beyond the plurality of readings to a celebration of de-centred productions of meanings for giving readers pleasure and empowerment. These theories motivated me to rethink the nature of translation and translation education and to develop the following notions that were to change the way I taught translation.

The first notion is that translation is not about identifying the single original meaning of a SL text or finding its single accurate equivalence in a TL text. Translation is a selective and interpretative process that involves examining the wide spectrum of possible meanings of a SL text, selecting one of them at the expense of the rest, and then selecting one of the many possible forms in the target language to represent that selected meaning. Thus translation is not an accurate cross-language and cross-cultural transmission of meaning or form but a process of active and selective interpretation and representation. Realizing the selective and interpretative nature of translation, I declared rhetorically, in a previous publication, the "death" of the translator and "birth" of the interpreter, i.e., a translator who consciously interprets rather than merely translates accurately (Zhong 1998).

The second notion is that translation is rarely an accurate transmission or reincarnation of the original meaning. As a matter of fact, whether equivalence can be achieved or not is off the point to me. A more relevant question is which of the many meanings to select and to translate and how to represent the selected meaning, as I am aware that, by selective interpretation and representation, translation legitimates only one single meaning at the expense of many alternative meanings. In a sense, translation is almost always a biased process that closes a SL text to only one interpretation and writes off other possible interpretations that are either unavailable or unacceptable to a translator trapped by his/her own political, social, cultural relations. However, this is not to exclude the possibility that readers of a translation may in turn produce aberrant interpretations of the translation.

The third notion is that translation is not a natural, equal or innocent communication of information but is rather an instrument that has been used by many political, cultural, social and especially colonial projects. Many aspects of translation, including the selection of SL texts (Venuti 1995), the recognition of and compliance with criteria (Zhong 1980) and the selection of translation techniques (Zhong 1999), are arguably biased toward certain projects and the interests of certain groups. Given 
the biased nature of translation, it is deceptive to require students to become merely accurate, faithful and objective translators. It makes more sense to develop in them the capacities to confront their own subjectivities, to use intellectual discretion, to make ethical and technical decisions, to seek information, to re-construct and manipulate knowledge, which all require greater extent of thinking.

The fourth notion, which is derived from the previous three, has profound implications for the teaching of translation. Because it involves selective interpretations and representations of meanings, we as educators must not disguise translation with a discourse of accuracy but rather should reveal its biased nature. Because translation is not an entirely natural, innocent, fair, accurate or objective process, we as educators must not be bothered about turning students into inhuman, selfless, accurate and objective translation machines with mechanical precision. Because students are autonomous, intellectual and mentally active subjects, we as educators must not contemplate mechanizing, standardizing and objectivizing their renditions by making them go through mechanical translation drills and by using the homogeneous criterion. Last but not least, because we would like students to develop a career that is professionally fulfilling and inspiring, we as educators must not dis-empower them by depriving them of their subjectivities and their right to think independently.

The notions discussed above have inspired me to transcend the discourse of accuracy and reorient the teaching of translation away from the elusive and exclusive discourse of accuracy (and faithfulness, objectivity, impartiality, etc.) to a new discourse. The new discourse centralizes the necessity of encouraging and developing students' active thinking, interactive learning and decision making and autonomous discretion. I have become more comfortable with this second discourse because, rather than subjugating students to some elusive, homogeneous, subjective and deceptive criteria like accuracy and objectivity, it is open-ended and promotes autonomous thinking and learning and, therefore, empowers students. Next, I will discuss three major implications of the alternative discourse to the teaching of translation.

1. The teaching of translation should encourage students to become thinking translators rather than accurate language facilitators willing to work in blind faith and loyalty. By thinking translators, I refer to people who use their intellectual capacities to translate. These capacities include seeking to be well informed of the various criteria and techniques, consciousness of the different purposes that different interpretations may serve, being open-minded to the various interpretations available to one text and willingness to make decisions. In addition, thinking translators should be both autonomous in and discreet about deciding what criteria, techniques and interpretations to select and adopt and what purposes to achieve through their translation. So, in order to train thinking translators, the teaching of translation should motivate students to develop their subjective discretion rather than injecting into them a set of universal rules, ethics and do's and don'ts.

Furthermore, the teaching of translation should aim to continuously cultivate in students a strong awareness of the social, cultural and political consequences of their consciousness, discretion and autonomy. Students must understand that, in a sense, thinking translators are condemned to the freedom of responsible interpretations and must not abuse their interpretative power. They must learn when and where to exert their interpretative power and when and where not to indulge in subjective interpretations. For example, under certain circumstances, especially when translating legal, medical and technical texts, they must know that they may have to adopt a literal, 
word-for-word translation style. But they must be also conscious that such accurate translation is a professional decision taken in due respect to established institutional procedures and in fairness to individuals rather than a necessity required by the existence of any true meaning or any natural objectivity or faithfulness. Such consciousness will push translators to continuously strive for fairer, more equitable and responsible renditions.

2. The teaching of translation should recognize that there are always alternative renditions, that a rendition always exists to the exclusion of other possible renditions, that no rendition is best, perfect or completely accurate and that one rendition may be more justifiable than another for certain reasons. That is to say, while translation is a competition of different interpretations, the learning of translation should never become a race towards the singular goal of accuracy or the "true meaning," especially not towards the teacher's standard rendition. Given the plurality of renditions, teachers should avoid using mechanical language drills that are designed to train standard translation habits and to produce the singular standard rendition. On the other hand, students should be given adequate chances to exert their interpretative power, to participate and compete in the interpretative process, and to try to justify their renditions by explaining the rationales behind the renditions.

3. The teaching of translation should create a student-centred, interactive learning environment in which teachers play the role of a facilitator of learning vis-à-vis students. It is important to see to it that students have an important say in selecting SL texts, in determining what criteria to adopt, in proposing translation methods, in producing and comparing interpretations, and in critiquing and justifying renditions. It is also important to encourage students to learn in an interactive environment where they can share and exchange different perspectives on a competitive but equal footing. By interacting with not only teachers but also with other students and external sources, students are more likely to think and to learn in an intellectual manner. The educators must derive their professional pleasure from seeing their students thinking and developing capacities for autonomous discretion and decision making rather than from injecting into students their own judgements, thought, experience and knowledge.

To sum up, the teaching of translation should empower students by encouraging them to confront and reflect on their subjectivities, to both celebrate the strength and recognize the weakness of their subjective, interpretative and intellectual power, and to become thinkers rather than blind followers. In other words, the teaching of translation should incorporate what Onosko and Newmann (1994) referred to as higher-order thinking characterized by "the resolution of conflicting views, tolerance for uncertainty and ambiguity, self-criticism, independence of judgement, and serious consideration of ideas that may challenge or undermine conventional wisdom" (1994, p. 46). I myself have tried to implement this new discourse in my own teaching of translation in recent years. Next, I will present a comparative case study of how I taught two translation lessons in order to explain the new discourse in a more tangible way.

\section{Case study: yours to reason why, yours not but comprehend and write}

I remember attending a translation lesson as a university student in the early 1980's. The SL text to be translated was a poem in memory of a late American president. The professor teaching that lesson enjoined us to not only comprehend and translate the poem accurately but also, more importantly, learn the accurate message from it 
about how to be a "cog and wheel." The line in the poem that anchored that accurate message read: yours not to reason why, yours but to do and die. As I tried to reorient the teaching of translation to thinking, I have reversed that quotation to: yours to reason why, yours not but to comprehend and write. Next, by presenting a case study that compares how I used to teach a translation lesson in mid 1990's and how I taught a lesson in early 2000 using the same SL text, I will demonstrate how I have reoriented my teaching of translation.

The SL text used in the two lessons was a Chinese article of about 400 characters, published in Min Pao, a Hong Kong based, internationally distributed Chinese language newspaper. The text, entitled Lianjue Zhixing Guojia de Renkou Zhengce (Resolutely Implement the National Population Policy), was about why China had to control its population growth, which was a contentious issue outside China. I selected this article for the lessons and for this case study because the National Accreditation Authorities for Translators and Interpreters (NAATI) distributed it as a sample test paper for its accreditation tests at the professional level. Moreover, I used it in my class both before and after I reoriented my teaching from pro-criteria and drill-based learning to pro-thinking learning. The article contained a central jargon, jihua shengyu, which was usually rendered into either birth control or family planning. While my summary discussion of the lessons will revolve around what my students and I did with the whole text, special mentioning will be made of the jargon as an example.

When I taught my students how to translate the article in the early 1990's, I was very keen for my students to conform to my set of criteria. As usual, I started by

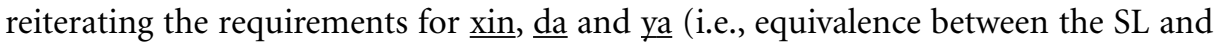
TL texts in meaning, expression and style), which I was to reiterate again and again during the lesson. Then, I led the students through the SL text, making sure that they got its true, original meaning. I picked a number of what I called language points, including jargons (e.g., jihua shengyu) and difficult sentences, and checked if the students knew their standard renditions or the best techniques to translate them. After the students finished the translation, I collected their assignments, which I marked against the criteria and the so-called standard translation. If I did not have much time, I would mark some of the assignments selectively or get the students to mark their own assignments against the standard version. I also let the students sight the standard version for them to recognize their own deviations from it. In short, every aspect of my teaching at the time was under the control of the discourse of accuracy.

Then, in the more recent lesson, which was conducted on a Monday, I tried to stimulate students' thinking in every aspect of the teaching. First, as I distributed copies of the SL text to the students, I asked them to scan it and urged them to raise questions regarding it and to comment on any questions raised by peer students and/ or by me. Then I invited the students to identify any difficulties that they thought they would confront when translating the text. I had the class discuss some of the questions and difficulties during the lesson and left others for the students to research into after class by themselves or in small groups. Next, I fixed a deadline for completing and submitting their translations and nominated two students to analyse them. Finally, I reminded the students that they could and should consult each other or myself and seek external help especially with English writing if it was their second 
language. Throughout the lesson, I repeatedly told students to "think," to "think again," to "think differently" and to "think from a different perspective." I believed that a lot of thinking was indeed required to raise questions and difficulties, discuss what caused the difficulties and suggest solutions to them. Rarely did I use the word accurately, faithfully or objectively.

The students had three days to complete their translations and were required to submit them by Thursday. Many of them did it interactively with one another by using some of the modern electronic technologies, including telephone, email and ICQ. After they submitted their translations to me in person, or by fax, or by email, I made two copies of each student's assignment. On the Thursday, the two student analysers each collected a copy of the translations from me for their project. Then when we met on the next Monday, the two students each presented a summary of his/her analyses to the class.

Undoubtedly, the process of translating the text, i.e., making one's interpretation and writing it down on paper, necessarily involved thinking. But what was important to me was that the other aspects, including pre-translation research/discussion and post-translation analyses, also engendered a great deal of thinking. Next, I will describe how some of these aspects engaged the students in active thinking.

One of the aspects that required a lot of thinking on the part of the students was when I invited them to raise questions and comment on those questions raised. The questions that were raised and commented on were concerned not only with the SL text/author (e.g., Who wrote the text? Why did he/she write the text?) but, more importantly, also with what meanings the students could actively and subjectively read into the text/author. For example, what were some of the common strategies used to implement jihua shengyu? Could alternative strategies have been adopted? What if China had not practised jihua shengyu? How would the newspaper's orientation and geo-political position influence its representation of the subject? Apparently, this latter type of questions generated much thinking by the students as they tried to produce their own readings and considered alternative readings by their fellow students.

Another aspect to make the students think was inviting them to identify potential difficulties that they thought they would encounter when translating the article, ranging from unfamiliar concepts to specialised jargons. I invited them to discuss some problems in class and leave some other problems for students' self-research after class. Џihua shengyu, a jargon with Chinese characteristics, was one of the problems raised during the class. When invited to say what they thought the jargon meant in English, the students came up with a number of renditions, including family planning, planned fertility, planned reproduction, fertility control, birth control and one child one family. Then, I asked the students to explain the rationales behind each rendition. Generally speaking, they were able to justify the renditions from a certain perspective. They pointed out, for example, that some (e.g., family planning and birth control) were widely accepted English equivalents of the jargon, that some (e.g., birth control) were the standard renditions used by China, that some (e.g., family planning and one child one family) conveyed the approximate meaning, and that some (e.g., planned fertility and planned reproduction) were more literal renditions.

In previous contacts with the class, I had always insisted that there were no accurate renditions but that there were different renditions and alternative renditions. I 
had also repeatedly emphasised that translation was all about closing the SL text to one interpretation and about selecting one interpretation of a SL text at the expense of alternative interpretations. In the present lesson, I went on to push the students to discuss what they thought about each rendition, including what exclusive and selective interpretation each of the renditions contained. The discussions around jihua shengyu led to a number of observations as follows:

- $\quad$ ihua shengyu was a complicated project involving many activities of different meanings to different people, including population control, forward planning, enforcement of control, education, incentives and punishments. None of the renditions were accurately or adequately equivalent to the jargon. For example, one child one family, which signified an apparent manifestation and result of Џihua shengyu, did not represent adequately many of the other activities.

- Those seemingly widely accepted or officially standard renditions might mislead readers of translations or distort the intended meaning of the SL text. For example, on the one hand, the use of English jargon family planning might camouflage some brutal methods used in China for the purpose of ذihua shengyu. On the other hand, control as in birth control, which might have a sinister connotation to English readers, was usually deemed as a neutral strategy of management and a necessity by many Chinese who had to bear the huge burden of over-population.

- There were no scientific, objective or neutral criteria to use for determining which of the renditions was accurate. Which rendition to adopt was largely a subjective, attitudinal decision by the translator and that decision could either serve or sabotage a project. Thus, it was understandable for someone sympathetic to Jihua shengyu to use family planning, for someone critical of the project to use birth control or even fertility control, or for someone to use one child one family in order to produce an easy reader.

Still another aspect, a post-translation one, to stimulate thinking was to have students undertake peer reviews of the assignments. This task, including analysing, assessing the translations and presenting a summary of the analyses and assessments to the class, was undertaken by all students by turns in my class and it constituted part of the course work and assessment. In the present lesson, two of the students collected copies of the assignments from me and analysed them separately. Then, they each presented a summary discussion of the assignments when the class met the next Monday. While the students were encouraged to explore any issues of importance to them and to structure their presentations in their own styles, they were supposed to cover at least three of the following areas:

- An introductory discussion of the translation criteria or theories selected for the analyses.

- A discussion of different renditions of selected parts of the SL text, speculating about the rationales behind them, and suggesting alternative ones.

- A critique of instances of renditions that are justifiable in conventional terms but contradictory to the political, social and cultural beliefs of the analysers.

- A criticism of instances, especially the ones identified in more than one assignment, which showed lack of thinking or research and therefore could not be justified.

- A display of two assignments selected by the analyser, one for its plentiful thoughtfulness and research and the other for its lack of thinking and research.

The presentations stimulated thinking by both the student analysers themselves and other students in the class (and the lecturer as well). The two analysers would have done a lot of thinking when they tried to select their own criteria, to compare 
different renditions and speculate about rationales behind them, to identify and discuss problems, and to publicly assess their fellow students' work in a justifiable manner. Furthermore, they would also have pushed other students to think by publicizing their own criteria, opinions and judgements, and by sharing their own experiences and techniques with the class. Their identity as equal learning partners to other students was also conducive to encouraging their peer students to challenge their points of view and to propose alternative ones.

When I taught the students to translate the same article on the earlier occasion, the lesson was centred on the discourse of accuracy, my professional expertise and experience, and my version of criteria and standards. By contrast, the recent lesson was conducted very differently in a number of ways. First, it transcended the discourse of accuracy, explored alternative possibilities outside standards, motivated the students to think and encouraged them to develop their own intellectual discretion. Secondly, it was delivered in an interactive style that was centred on students, on their initiatives to identify, analyse and solve problems and on the exchanging and sharing of perspectives, information and ideas between equal learning partners. Thirdly, by promoting thinking and interaction, it offered an intellectually challenging, fulfilling and empowering learning experience for the students. Last but not least, I as the lecturer of the class also felt intellectually stimulated and fulfilled with the teaching.

\section{Conclusion}

In summary, this article has attempted to challenge the discourse of accuracy, which has dominated the practice and teaching of translation in both China and Australia. I started the challenge with a discussion of a paradox created by the discourse, pointing out that, while tertiary education was intended to nurture students' ego and creativity, the discourse constructed students as mindless, unthinking and mechanical language facilitators. I went on to propose that a number of recent critical theories, including post-structuralism and cultural studies, could help the teaching of translation transcend the impasse of accuracy. Inspired by the theories, I pointed out that translation was always a process of selective interpretations and representations, that translation was biased towards selected projects and selected interests, and that the teaching of accuracy, faithfulness and objectivity was deceptive rhetoric. Then, I proposed to replace the discourse of accuracy with an alternative discourse in the teaching of translation, a discourse that centralized thinking and development of students' subjective intellectual capacities. In order to illustrate the merits of the new discourse in pedagogy, I presented a case study that compared two of my lessons, one before and the other after I reoriented my teaching. Through a description of the recent lesson, I explained how I stimulated the students to think, to use their subjective intellectual capacities and to have an intellectually challenging and fulfilling learning experience. To conclude the article, I would like to say that the transcendence of the discourse of accuracy has given me plenty of thinking and job satisfaction too. 


\section{NOTES}

1. For example, the National Accreditation Authority for Translators and Interpreters (NAATI) of Australia instructs that its members "shall endeavour to the best of their ability to translate and interpret accurately by ensuring that the true meaning of words, concepts, statements and bodily expressions is conveyed" (NAATI 1990b, p. 39).

2. The cliché that those who can write write and those who cannot write translate in some way substantiates the negative perception about translators.

\section{REFERENCES}

Barthes, R. (1977): Image-Music-Text, translated by S. Heath, London: Fontana.

Fiske, J. (1987): Television Culture: Popular Pleasures and Politics, London: Routledge.

Fiske, J. (1998): “The popular economy," in J. Storey (ed.) Cultural Theory and Popular Culture, London: Prentice Hall.

Hall, S. et al. (eds) (1980): Culture, Media, Language, London: Hutchinson.

NAATI (1990): Walking A Tightrope, Canberra: The National Accreditation Authority for Translators and Interpreters.

NAATI (1990b) Candidates' Manual, Canberra: The National Accreditation Authority for Translators and Interpreters.

Onosko, J. and F. Newmann (1994): "Creating more thoughtful learning environments," in J.N. Mangieri and C.C. Block (eds) Creating Powerful Thinking in Teachers and Students: Diverse Perspecitves, Fort Worth: Harcourt Brace College Publishers.

Venuti, L. (1995): The Translator's Invisibility: A History of Translation, London: Routledge.

WeEdon, C. (1998): "Feminism \& the principles of poststructuralism," in J. STOREy (ed.), Cultural Theory and Popular Culture, London: Prentice Hall, 172-184.

Zhong, S. K. (1980) A Handbook of Translation, Beijing: The Commercial Press.

Zhong, Y. (1998): "Death of the translator and birth of the interpreter," Babel, 44: 4, 336-347.

ZHoNG, Y. (1999): "To transliterate or not to transliterate, that is the question (of national identity): with special regard to Chinese transliteration vs translation of English commercial terms," Journal of Translation Studies, 3, March, 81-95. 